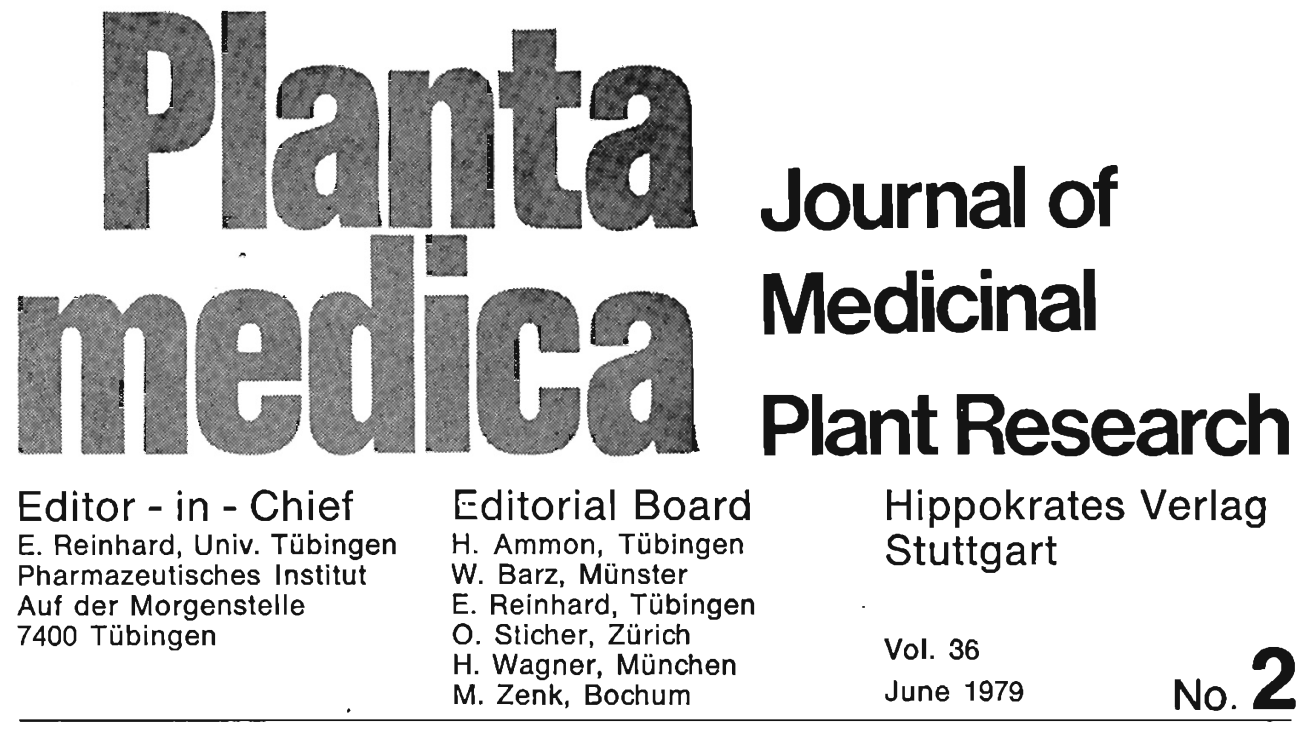

Review Amricle

\title{
Biosynthesis and Metabolism of the Tropane Alkaloids
}

\section{Edward Leete}

Natural Products Laboratory, School of Chemistry, University of Minnesota.

Key Word Index: Tropane Alkaloids; Biosynthesis; Metabolism; Tropic Acid; Tiglic Acid; Hydroxylation of Tropine.

\section{Abstract}

The origin of both the basic (tropane derivatives) and acidic (tropic acid, tiglic acid, benzoic acid) moieties of these ester alkaloids is reviewed. Subsequent metabolism (mostly by oxidation reactions) of the tropine half of these alkaloids is discussed.

\section{Introduction}

The tropane alkaloids are characterized by the presence in their molecules of the 8-azabicyclo [3.2.1] octane ring system (I). Its $\mathrm{N}$-methyl derivative is trivially known as tropane. Many of the alkaloids are derivatives of tropine (II) which is tropan- $3 \alpha-o l$. Tropine, having 


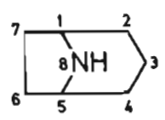

1

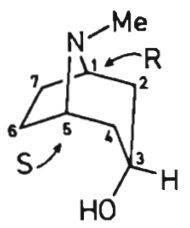

Tropine II<smiles>CN1[C]2CC[C]1C[C](OC(=O)C(CO)c1ccccc1)C2</smiles>

Hyoscyamine III<smiles>CC(C)=CC(=O)OC1CC2C(O)C(C1)N(C)C2O</smiles>

Meteloidine VI<smiles>[R]c1oc2c(c(=O)c1C)C1CCC(C2)N1C</smiles>

Bellendine $\mathrm{R}=\mathrm{H}$ IX

Ferrugine $R=\operatorname{Me} X$<smiles>CN1CC2CC(OC(=O)C(CO)c3ccccc3)CC1C1OC21</smiles>

Scopolamine IV<smiles>CC(=O)C1CC2CCC(C1)N2C(C)=O</smiles>

Cocaine VII<smiles>CN1C2CCC(C(=O)c3ccccc3)C1CC2</smiles>

2a-Benzoyltropane XI<smiles>CN1C2CCC1CC(OC(=O)C(O)Cc1ccccc1)C2</smiles>

Littorine $v$<smiles>CN1[C]2CC[C]1C[C](OC(=O)c1cccc(O)c1)C2</smiles>

Cochlearine VIII

$2 \beta$-Benzyl-3 $\beta$-acetoxy-

tropane $x I I$

Fig. 1. Tropane Alkaloids.

a plane of symmetry, is optically inactive, however it should be noted that C-1 (as depicted in II) has the $R$-configuration, and C-5 has the $S$-configuration, and these two positions can be different with respect to an enzyme.

Some of the alkaloids whose biosynthesis will be discussed in this review are illustrated in Fig. 1. Hyoscyamine (III) and scopolamine (also known as hyoscine) (IV) are found in a large number of Datura species. Atropine is the racemic form of hyoscyamine, and racemization of hyoscyamine usually occurs during its isolation from plants. On the other hand scopolamine seems to be 
much more resistant to racemization. Recently discovered alkaloids containing the tropane ring system include bellendine (IX) [57], and ferrugine (X) [10] containing a fused $\gamma$-pyrone ring. Alkaloids (XI) and (XII) are novel in having a benzoyl or benzyl group at C-2 [52, 53]. Extensive work involving labelled precursors has been carried out on both the tropane half of these alkaloids, and the various acids (tropic, tiglic, benzoic) which are present in these alkaloids esterified to tropane alcohols.

\section{Origin of the Tropane Ring System}

Ornithine, and related amino acids (glutamic acid, proline) are precursors of the pyrrolidine ring of tropine [26, $27,39,48,49]$ Ornithine is incorporated into the tropane ring system unsymmetrically. It was found that tropine (present in hyoscyamine) derived from $\left[2-{ }^{14} \mathrm{C}\right]$ ornithine was labelled only at the $\mathrm{C}-1$ bridgehead carbon. On the other hand $\left[5-{ }^{14} \mathrm{C}\right]$ proline labels only the C-5 position of tropine [49]. Work on the origin of the nitrogen in tropine is equivocal. We [32] found that both amino groups of ornithine were apparently incorporated into hyoscyamine and scopolamine produced in a rootculture of Atropa belladonna. However the specific incorporation of ${ }^{14} \mathrm{C}$ (located at $\mathrm{C}-2$ of ornithine) was about three times higher than the nitrogen (located at the $a$ - or $\delta$-positions). SPENSER [68] found similar results. On the other hand LIEBISCH and SCHÜTTE [49] reported that $\left[2-{ }^{14} \mathrm{C}, \delta-15 \mathrm{~N}\right]$ ornithine was incorporated into the tropane moiety of hyoscya- mine and scoplamine with little change in the ${ }^{14} \mathrm{C}:{ }^{15} \mathrm{~N}$ ratio, while $\left[{ }^{-14} \mathrm{C}\right.$, $\left.\alpha-{ }^{15} \mathrm{~N}\right]$ ornithine yielded tropine containing much less ${ }^{15} \mathrm{~N}$ than ${ }^{14} \mathrm{C}$. These results suggest that it is the $\delta$-amino group of ornithine which is a precursor of the tropane nitrogen. However the calculated ${ }^{14} \mathrm{C}$ specific incorporations reported in this publication are too high by a factor of 10 . If these results are real they indicate that the $\delta$-amino group of ornithine is ten times more efficient as a source of the tropane nitrogen atom, than is the carbon skeleton of ornithine a source of the carbons of the pyrrolidine ring. I believe that extensive loss of ${ }^{15} \mathrm{~N}$ from the amino groups of ornithine occurs by transamination reactions during the feeding experiments, all of which involved root cultures. The incorporation of glutamic acid and proline is considered to occur via ornithine, and the metabolic relationship of these amino acids is illustrated in Fig. 2. SPENSER [55] has shown that ornithine is converted to proline via $a$-keto- $\delta$-amino valeric acid in Datura species, and presumably this reaction is reversible.

Figure 3 illustrates how ornithine is converted to tropine. We presently consider that ornithine is incorporated via $\delta$-N-methylornithine (XIV) $[1,2,3]$, although it must be admitted that this amino acid has not yet been detected in Datura or related species. Earlier work [58] which apparently implicated $\alpha-\mathrm{N}$ methylornithine rather than the $\delta$-isomer as a precursor of tropine, was discounted when it was shown [20] that these authors were using non-authentic $\alpha$ - and $\delta$-N-methylornithines in their tracer experiments. It was shown that 

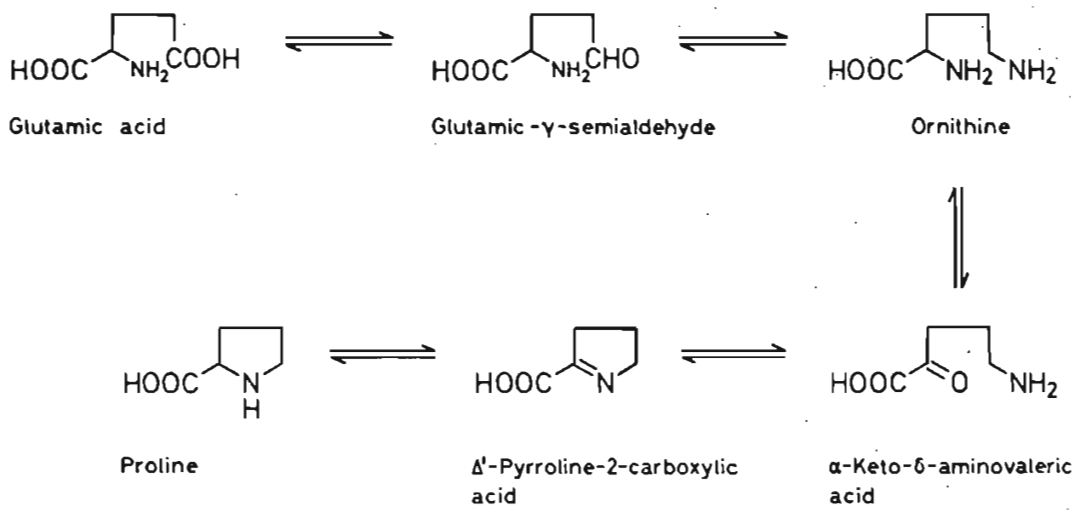

Fig. 2. Metabolic Relationship of Glutamic Acid, Ornithine and Proline.
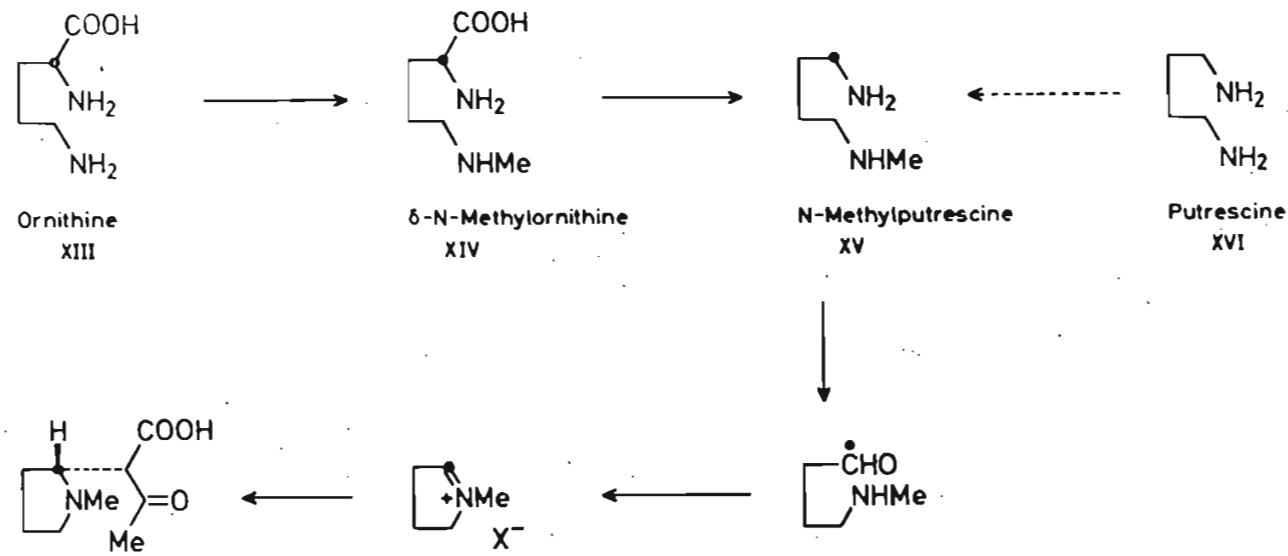

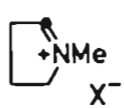

XVIII

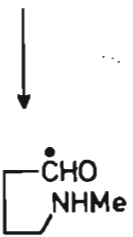

4-Methylaminobutanal
XIX
Hygrine-a-carboxylic

acid XVII<smiles>CNC</smiles>

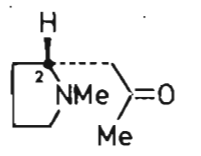

$(+)-(2 R)-$ Hygrine $\mathrm{xX}$

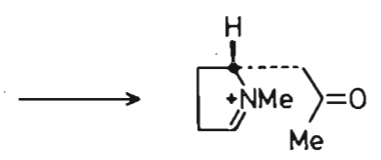

Dehydrohygrine

XXI

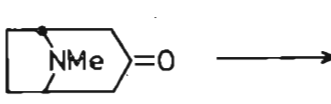

Tropinone

XXII

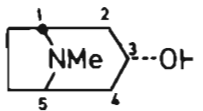

Tropine

II

Fig. 3. Metabolism of Ornithine to Tropine.

[methyl- $\left.{ }^{14} \mathrm{C}\right]-\delta$-N-methyl-[2- $\left.{ }^{14} \mathrm{C}\right]$ orni- positions indicated that the $\delta$-N-methylthine was incorporated into hyoscya- ornithine was incorporated without any mine labelling $\mathrm{C}-1$ and the $\mathrm{N}$-methyl cleavage of the $\mathrm{N}$-methyl group. The group. The ratio of activity at these two next step is a decarboxylation to yield 
$\mathrm{N}$-methylputrescine (XV) an established precursor of tropine [45, 47]. $\mathrm{Pu}$ trescine (XVI) has also been shown to be a precursor of the tropane alkaloids $[23,36,48,50]$. However putrescine cannot be a free intermediate between ornithine and the tropane skeleton, since such a symmetrical intermediate would result in the formation of tropine labelled equally at $\mathrm{C}-1$ and $\mathrm{C}-5$ after the administration of $\left[2-{ }^{14} \mathrm{C}\right]$ ornithine. We suggest that the utilization of putrescine represents an "aberrant" biosynthesis. By this we mean that putrescine is not part of the biosynthetic pathway, however the plant contains enzymes which are capable of converting the administered putrescine to $\mathrm{N}$-methylputrescine. Oxidation of the primary amino group of (XV) affords 4-methylaminobutanal (XIX), which was detected in Datura plants which had been fed $\left[2-{ }^{14} \mathrm{C}\right]$ ornithine [56]. The cyclized form of this amino aldehyde is the Nmethyl- $\Delta^{1}$-pyrrolinium salt (XVIII). Carbons 2, 3, and 4 of tropine are derived from acetic acid $[24,46]$ and it is assumed that the acetate is incorporated via acetoacetic acid or some suitably activated derivative such as its coenzyme A ester. The result of such a condensation between (XVIII) and acetoacetate is hygrine- $\alpha$-carboxylic acid (XVII) which on decarboxylation affords hyg- rine (XX) an established precursor of tropine $[46,59]$. It has been recently shown [54] that it is the (+)-(2R)-hygrine $(\mathrm{XX})$ enantiomer which serves as a precursor of the tropane alkaloids of Datura innoxia. The incorporation of $(-)-(2 S)$-hygrine, although lower than its $2 R$ isomer (3.7 to 10.7 times less efficient), was never-the-less significant. The incorporation of the $2 S$-isomer could be rationalized by suggesting that some racemization occurred during the feeding period ( 7 days). Racemization occurs readily in neutral or basic solution by the mechanism illustrated in Fig. 4. It is of interest to note that $(2 R)$ hygrine is formed by an attack of the acetoacetate on the pyrrolinium salt on the opposite side from the one involved in the formation of natural $(-)-2$ 'S)nicotine (XXIII). This result is illustrated in Fig. 5. Final steps to yield tropinone (XXII) are considered to involve the hypothetical intermediate dehydrohygrine (XXI). Tropinone has been isolated from Cyphomandra species [16]. Stereospecific reduction of tropinone yields tropine.

It is instructive to follow the biosynthetic pathways whereby $\left[1-{ }^{14} \mathrm{C}\right]$ acetate is incorporated into tropine (Figure 6). It has been shown that glutamic acid isolated from wheat plants was labelled mostly at C-1 and C-5 [11]. This result

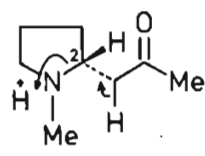

$(+)-(2 R)-$ Hygrine
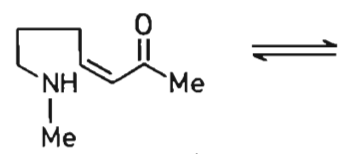

$(-)-(2 S)$-Hygrine

Fig. 4. Mechanism for the Racemization of Hygrine. 


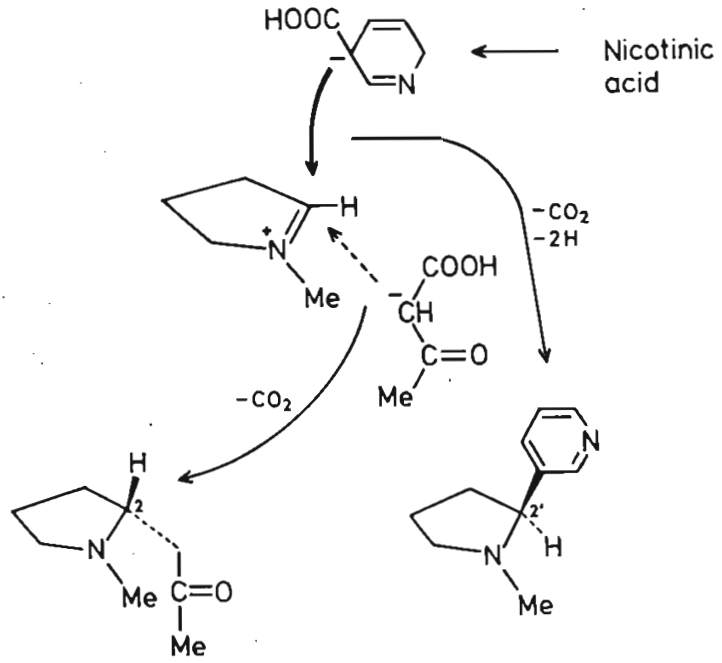

$(+)-(2 R)-$ Hygrine

$(-)-(2 ' S)-$ Nicotine XXII!

Fig. 5. Nucleophilic Attack of N-Methyl- $\Delta^{1}$-pyrrolinium Salt from the $\alpha$ - and $\beta$-face.

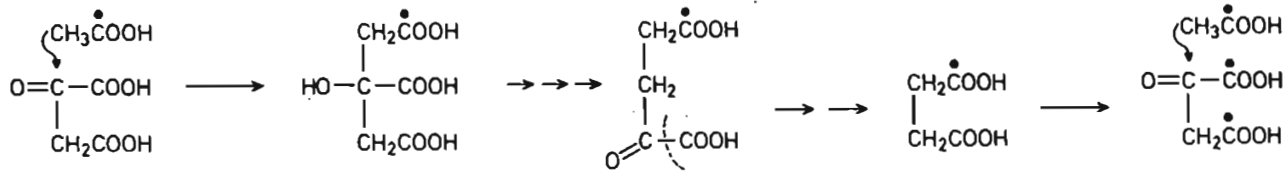<smiles>CCCCC(N)C(=O)O</smiles>

$\left[1,5^{14} \mathrm{c}\right]$-Ornithine $\left[1,5^{16} \mathrm{c}\right]$-Glutamate

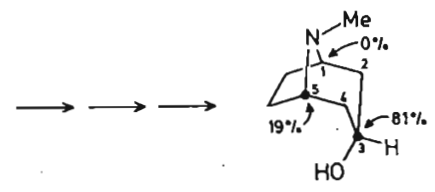

Tropine

Fig. 6. The Incorporation of $\left[1-{ }^{14} \mathrm{C}\right]$ Acetate into Tropine. 
is in accord with the expected incorporation of acetate into the Krebs cycle. The ornithine derived from this glutamate would be labelled at C-1 and C-5. Incorporation of this ornithine as previously described yields tropine labelled at the C-5 bridgehead position with no label at C-1 [12]. Labelling at C-3 results from the incorporation of the $\left[1,3^{-14} \mathrm{C}\right]$ acetoacetate, and the higher level of activity found at this position $(81 \%)$ is in accord with the administered acetate being closer biochemically to this part of the molecule.

It seems reasonable to propose that the tropane moiety of cocaine (VII), ie. ecgonine (XXIV) is produced by a slight modification of the biosynthetic route illustrated in Fig. 3, whereby the carboxyl group of hygrine- $\alpha$-carboxylic acid (XVII) is retained, as illustrated in Fig. 7. However no definitive results have been obtained on the biosynthesis of the tropane moiety of this important medicinal agent. The administration of $\left[1-{ }^{14} \mathrm{C}\right]$ acetate to Erythroxylon coca
[46] yielded radioactive cocaine. However most of the activity $(\sim 60 \%)$ was apparently located on the ester methyl group. Another 30\% was present on the carbonyl group of the benzoyl residue, and only small amounts were present in the tropane ring system. We [42] and others [69] have also failed to observe the incorporation of likely precursors (putrescine, ornithine, $\mathrm{N}$ methyl- $\Delta^{1}$-pyrrolinium salt) into the pyrrolidine ring of cocaine.

Reports [25] that labelled succinic acid was incorporated into hyoscyamine, led Barelle and Gros [3] to repeat this experiment, with the finding that non-specific labelling occurred.

The tropane alkaloids having a $\mathrm{C}_{6}-$ $\mathrm{C}_{1}$ group attached to $\mathrm{C}-2$ of the tropane molecule are plausibly derived by reaction of the N-methyl- $\Delta^{1}$-pyrrolinium salt with a poly-ketide having benzoic acid as its starter unit, as illustrated schematically in Fig. 8. This Figure also depicts the formation of bellendine (IX) from the pyrrolinium salt and a poly-
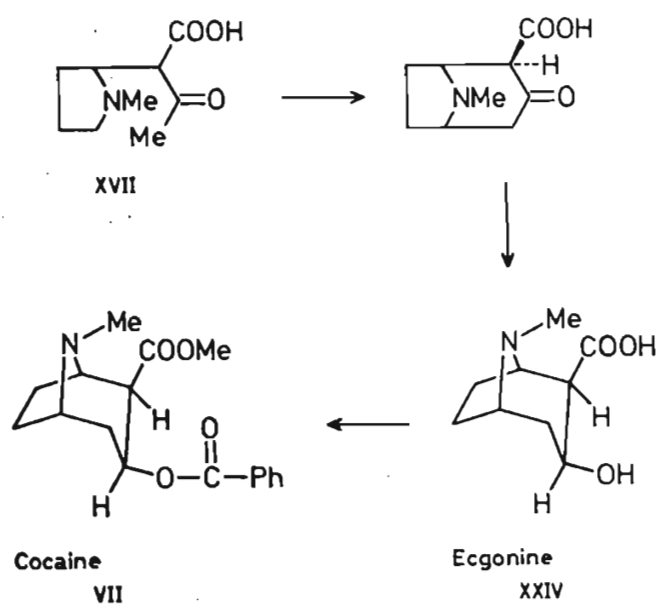

Ecgonine

XXIV

Fig. 7. Hypothetical Biosynthesis of Cocaine. 


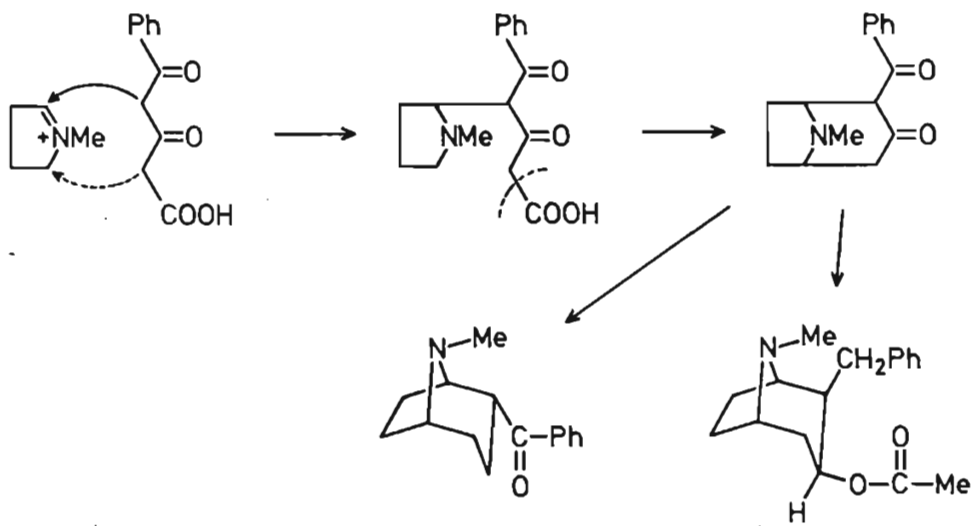

XI

xII
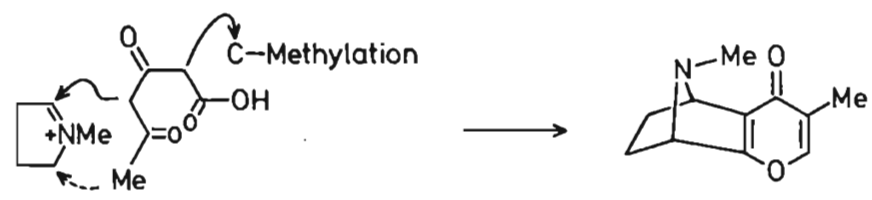

Bellendine IX

Fig. 8. Hypothetical Biosynthesis of Some Novel Tropane Alkaloids.

acetyl chain which has undergone $\mathrm{C}$ methylation (from methionine) at a reasonable position (between two carbonyl groups).

\section{Oxidation of the Tropane skeleton}

It was shown that the pyrrolidine ring of meteloidine (VI) is derived from ornithine [41] and the hydroxyl groups at the 6 and 7-positions are apparently introduced at a late stage in the biosynthetic sequence, after formation of the tropine ring system [28]. Extensive work by WOOLLEY and coworkers [6, $8,9]$ and ourselves [37] indicate that meteloidine is formed by the hydroxylation of $3 \alpha$-tigloyloxytropane (XXV) (also known as tigloidine), probably via
$3 \alpha$-tigloyloxytropan-7 $\beta$-ol (XXVII). One problem in studying the origin of these tigloyloxytropanes is the facile hydrolysis which these compounds undergo in the plant in the course of feeding experiments. The dihydroxylation which occurs at C-6 and C-7 in the formation of meteloidine proceeds with retention of configuration [38]. This result is typical of direct hydroxylations at saturated carbon atoms [7], and was established by labelling tropine stereospecifically wtih tritium at the $6 \beta$ and $7 \beta$-positions.

A related oxidation of the tropine ring system occurs in the formation of scopolamine. Long ago it was established that this alkaloid is a metabolite of hyoscyamine $[19,63,64,65,66]$, and the reaction proceeds via 6 -hydro- 
<smiles>CC(C)=C(C)C([13CH2])=O</smiles>

Tropine II 3a-Tigloyloxytropane $x x V$

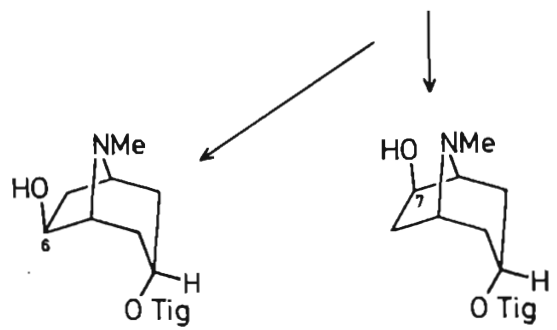

$x \times y 1$

xxvII
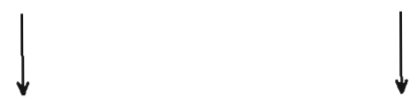

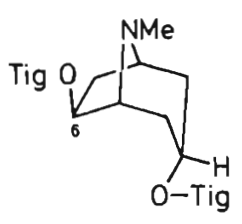

XXVIII

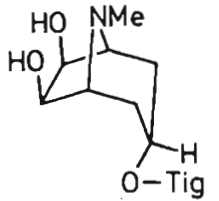

Meteloidine VI

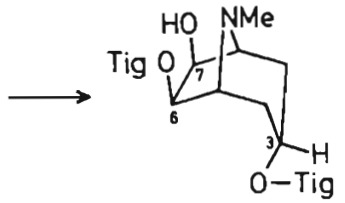

$x x I X$

Fig. 9. Biosynthesis of Some Tigloyloxytropanes.

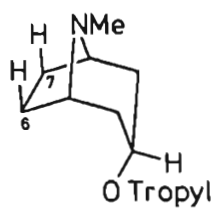

Hyoscyamine III

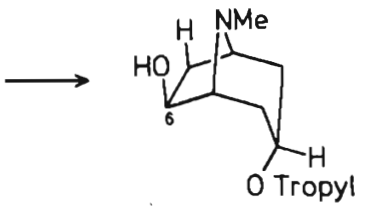

6-Hydroxyhyoscyamine<smiles>C=[Tl]</smiles><smiles>CN1[C@H]2C[C@@H]([OH2+])C[C@@H]1C1OC12</smiles>

Scopolamine iv

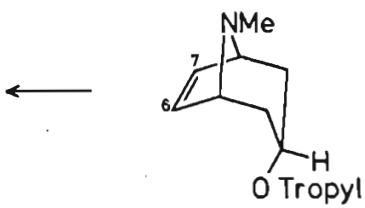

6,7-Dehydrohyoscyamine XXXII

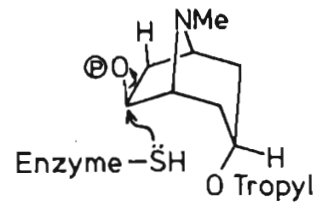

$x x x I$

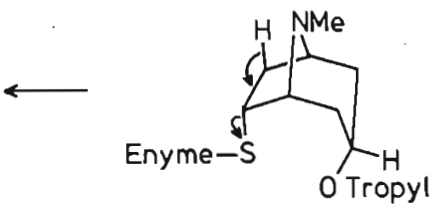

XXXIII

Fig. 10. Metabolism of Hyoscyamine to Scopolamine. 
xyhyoscyamine (XXX) and 6,7-dehydrohyoscyamine (XXXII). This overall reaction also involved the loss of both the $\beta$-hydrogens at C- 6 and C-7 [38]. This result indicates that the conversion of 6-hydroxyhyoscyamine to the dehydro-compound (XXXII) involves a cis-dehydration. This is unusual, but not without precedence [13]. We suggest that the dehydration takes place by a two step mechanism illustrated in Fig. 10. A phosphorylated 6-hydroxyhyoscyamine (XXXI) could be attacked by a nucleophilic reagent (represented here by the SH-group of an enzyme) to afford (XXXIII). Then the double bond would be generated by a trans-elimination.

\section{Origin of the Acid Moieties of the Alkaloids}

\section{Tropic Acid and Related Aromatic} Acids

Tropic acid having the $(S)$-configuration (XXXVIII) is found in the alkaloids hyoscyamine and scopolamine. Its biosynthesis has been the subject of extensive investigations by several groups in the past 18 years. This work has been reviewed [29] and I will confine my remarks to recent developments. Tropic acid is formed by the rearrangement of the side chain of phenylalanine (XXXVI) and it has been shown that this rearrangement is intramolecular [34]. This important result was obtained by labelling phenylalanine at $\mathrm{C}-1$ and $\mathrm{C}-3$ with carbon-13, so that the administered amino acid contained $81 \%$ of the doubly labelled species. Examination of the ${ }^{13} \mathrm{C}$ NMR spectra of the resultant labelled hyoscyamine and scopolamine revealed the presence of satellite peaks, due to spin-spin coupling of contiguous ${ }^{13} \mathrm{C}$ atoms which arose by. a 1,2-intramolecular rearrangement. The mechanism of this rearrangement is unknown. Compounds which are metabolically related to phenylalanine, such as phenylpyruvic acid (XXXV) and phenyllactic acid (XXXIV) are also incorporated into tropic acid [17, 33]. Phenyllactic acid is esterified with tropine in the alkaloid littorine (V) and its formation from phenylalanine has been established [18]. When phenylalanine was labelled with tritium in its side chain it was found [67] that the tritium at C-2 was not incorporated into tropic acid, however one of the tritiums at C-3 was retained in the ultimate tropic acid [43]. Dalton [15] has proposed a reasonable hypothesis for this rearrangement, and it is reproduced in Fig. 11. One experimental fact which this scheme does not take into account is the finding [31] that 2-formylphenylacetic acid (XXXVII) failed to serve as a precursor of tropic acid in Datura.

The same rearrangement of the phenylalanine side chain is involved in the biosynthesis of the fungal product tenellin (XL). The intramolecular nature of this reaction was also established by means of ${ }^{13} \mathrm{C}$ NMR [35]. 2-Formylphenylacetic acid, or its coenzyme A ester (IXL) would be a plausible intermediate to condense with a polyketide chain derived from acetate and the methyl groups of methionine as illustrated in Fig. 12. Hydroxylation of the phenyl ring apparently occurs at a late stage in the biosynthesis.

Despite claims to the contrary [22, 70] we [34] have been unable to sub- 

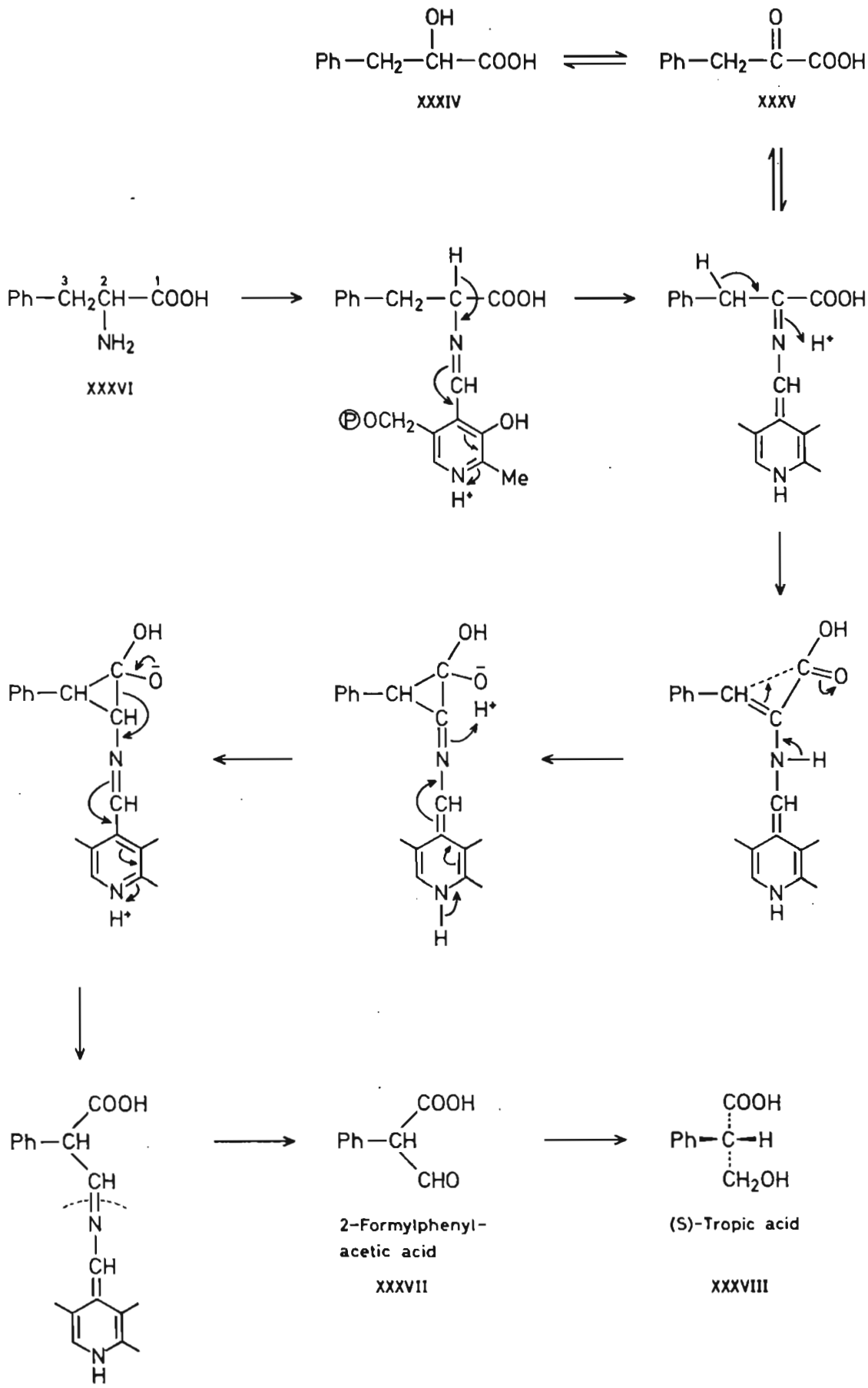

Fig. 11. Hypothetical Mechanism for the Formation of Tropic Acid from Phenylalanine. 
$5 \mathrm{MeCOOH}$

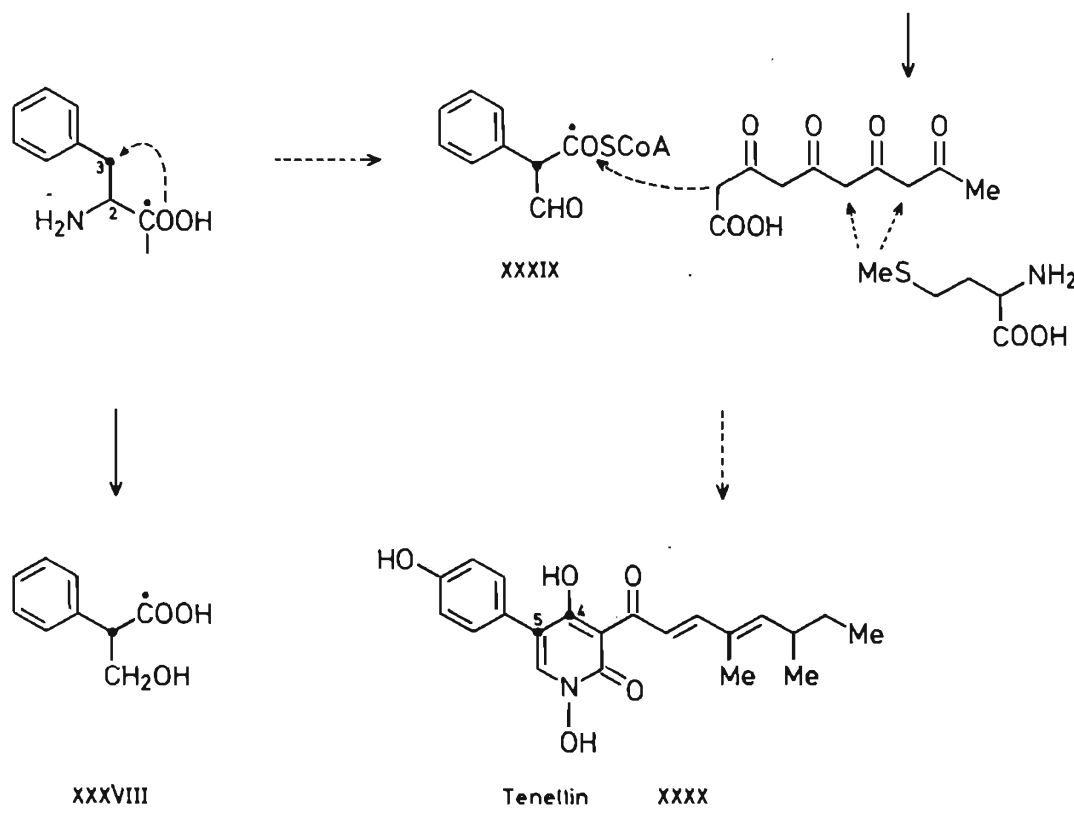

Fig. 12. Biosynthesis of Tenellin.

stantiate the incorporation of phenylacetic acid into tropic acid. Several groups $[17,43]$ have reported that cinnamic acid does not serve as a precursor of tropic acid. We also found that cinnamoyltropine is not converted directly to the tropane alkaloids of Datura stramonium. The results obtained [33] indicated that this ester was hydrolysed in the plant to tropine and cinnamic acid, only the former compound being incorporated into hyoscyamine and scopolamine. However it has been recently reported [61] that $\left[2-{ }^{14} \mathrm{C}\right]$ cinnamic acid yielded hyoscyamine which was labelled specifically on the hydroxymethyl group of tropic acid. However I have grave doubts about the validity of this observation, especially after examination of the dissertation [60] from which the published results were presumably obtained.
The benzoyl moiety of cocaine is derived from phenylalanine [21], by cleavage of the side chain between C-2 and $\mathrm{C}-3$. The formation of benzoate by the $\beta$-oxidation of cinnamic acid (formed from phenylalanine by the action of the enzyme phenylalanine-ammonialyase) has been established by ZeNK [73]. $\mathrm{A} \mathrm{C}_{6}-\mathrm{C}_{1}$ fragment derived from phenylalanine is also involved in the biosynthesis of ephedrine [72].

The $m$-hydroxybenzoic acid residue found in the alkaloid cochlearine (VIII), Fig. 1 is also formed from phenylalanine, apparently via m-tyrosine [44].

\section{Tiglic Acid}

This compound which is the acid moiety of meteloidine and several other alkaloids is formed from L-isoleucine (XLI) $[40,71]$ in Datura species, and current evidence suggests that the pathway whereby it is formed is similar to 

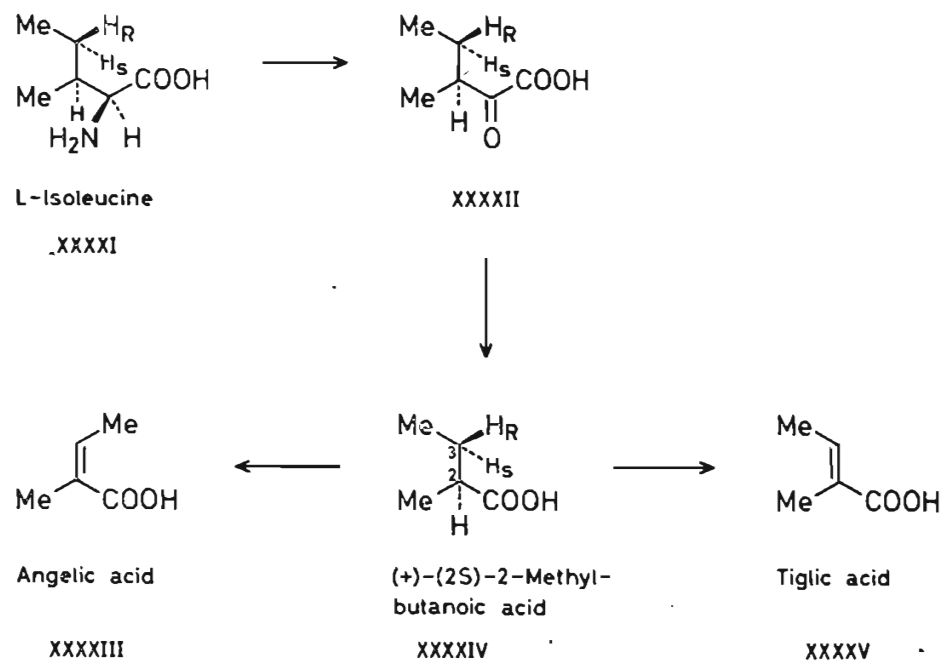

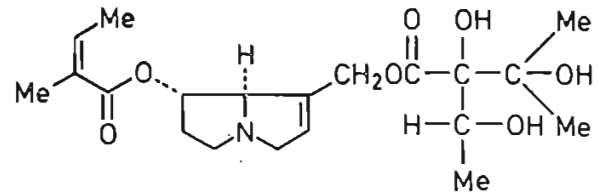

Heliosupine<smiles>CN1CCC2CC(CC3CCSS3)OC(=O)C21</smiles>

$x \times X X V I I$

Fig. 13. Biosynthesis of Tiglic and Angelic Acids.

the one previously established in animal systems (pig heart and rat liver) [62]. The immediate precursor of tiglic acid is 2-methylbutanoic acid [5,30] and it seems probable (although this has not been proven) that it is the (2S)-enantiomer (XLIV) which is involved. Another point of interest, is which hydrogen (the pro- $R$ or pro- $S$ ) is lost from $\mathrm{C}-3$ in the final dehydrogenation to yield tiglic acid. Angelic acid (XLIII), the geometric isomer of tiglic acid, is present as an ester in the alkaloid heliosupine (XLVI), and Crout [14] has shown that it is also formed from isoleucine. BASEY and Woolley [5] found that angelic acid was not isomerized to tiglic acid in $\mathrm{Da}$ tura innoxia.
A novel aliphatic acid, 1,2-dithiolane3-carboxylic acid is present in the alkaloid (XLVII) which was isolated from the tropical mangrove Bruguiera sexangula [51]. No work has been carried out on its biosynthesis, however its formation from butanoic acid would seem reasonable, analogous to the formation of lipoic acid from octanoic acid.

\section{Acknowledgments}

Our work described in this review (Contribution No. 158) was supported by a research grant, GM-13246 from the National Institutes of Health, U. S. Public Health Service. I dedicate this paper to Leo Marion with whom I 
started work on the biosynthesis of the tropane alkaloids some 25 years ago at the National Research Council of Canada.

\section{References}

1. Ahmad, A. and E. Leete: Biosynthesis of the tropine moiety of hyoscyamine from $\delta$-N-methylornithine. Phytochemistry 9, 2345 (1970).

2. Baralle, F. E. and E. G. Gros: Biosynthesis of cuscohygrine and hyosciamine in Atropa belladonna from DL- $\alpha-\mathrm{N}$-methyl- $\left[{ }^{3} \mathrm{H}\right]$ ornithine and DL- $\delta$-N-methyl- $\left[{ }^{3} \mathrm{H}\right]$ ornithine. Chem. Commun. 721 (1969).

3. Baralle, F. E. and E. G. Gros: Biosynthesis of cuscohygrine and hyosciamine in Atropa belladonna from $\mathrm{DL}-\alpha-\mathrm{N}$-methyl- ${ }^{3} \mathrm{H}$-ornithine, DL- $\delta$-N-methylornithine and succinic acid-1, $4^{-14} \mathrm{C}$. Anales Asoc. Quim. Argentina 58, 299 (1970).

4. Basey, K. and J. G. Woolley: Biosynthesis of the tigloyl esters in Datura: The role of 2-methyl butyric acid. Phytochemistry 12, 2197 (1973).

5. Basey, K. and J. G. Woolley: Biosynthesis of the tigloyl esters of Datura: Cis-trans isomerism. Phytochemistry 12, 2883 (1973).

6. Basey, K. and J. G. Woolley: Biosynthesis of ditigloyl esters of di- and tri-hydroxy tropanes in Datura. Phytochemistry 14, 2201 (1975).

7. Bentley, R., in "Molecular Asymmetry in Biology", Vol. 2, p. 259, 274, 1970 Academic Press.

8. Beresford, P. J. and J. G. Woolley: Biosynthesis of $3 \alpha, 6 \beta$-ditigloyloxy tropane and $3 \alpha, 6 \beta$-ditigloyloxytropan-7 $\beta$-ol in Datura. Phytochemistry 14, 2205 (1975).

9. Beresford, P. J. and J. G. Woolley: Competitive feeding experiments with tropine in Datura. Phytochemistry 14, 2209 (1975).

10. Bick, R. C., J. W. Gillard and M. Woodruff: Ferrugine: a novel tropane alkaloid. Chem. and Ind. (London) 794 (1975).

11. Bilinski, E. and W. B. McConnell: Studies on wheat plants using carbon-14 compounds. III. The utilization of acetate for amino acid biosynthesis. Can. J. Biochem. Physiol. 35, 357-363 (1957); IV. Distribution of carbon-14 in glutamic acid, aspartic acid, and threonine arising from acetate $-1{ }^{14} \mathrm{C}$ and $-2-{ }^{14} \mathrm{C}$. ibid., 35, 365-371 (1957).

12. Bothner-By, A. A., R. S. Schutz, R. F. Dawson and M. L. Solt: The asymmetric incorporation of isotopic label in the biogenesis of hyoscyamine. J. Am. Chem. Soc. 84,52 (1962).

13. Butler, J. R., W. L. Alworth and M. J. Nugent: Mechanism of dehydroquinase catalyzed dehydration. I. Formation of a Schiff base intermediate. J. Am. Chem. Soc. 96, 1617 (1974).

14. Crout, D. H. G.: Pyrrolizidine alkaloids. Biosynthesis of the angelate component of heliosupine. J. Chem. Soc. (C) 1233 (1967).

15. Dalton, D.: "An Alkaloid Primer", New York 1978, Marcel Dekker.

16. Evans, W. C., A. Ghani and V. A. Woolley: Alkaloids of Cyphomandra betacea Sendt. J. C. S. Perkin I. 2017 (1972).

17. Evans, W. C. and J. G. Woolley: Biosynthesis of $\mathrm{C}_{8}-\mathrm{C}_{3}$ acids in Datura innoxia. Phytochemistry 15, 287 (1976).

18. Evans, W. C. and V. A. Woolley: Biosynthesis of the (+)-2-hydroxy-3-phenylpropionic acid moiety of littorine in Datura sanguinea and Anthoceucis littorea. Phytochemistry 8, 2183 (1969).

19. Fodor, G., A. Romeike, G. Janzso and I. Koczor: Epoxidation experiments in vivo with dehydrohyoscyamine and related compounds. Tetrahedron Lett. No. 7, 19 (1959).

20. Gilbertson, T. J. and E. Leete: Biosynthesis of the Nicotiana alkaloids. XII. The incorporation of alpha and delta-N-methylornithine into the pyrrolidine ring of nicotine. J. Am. Chem. Soc. 89, 7085 (1967).

21. Gross, D. and H. R. Schütte: Phenylalanin als Vorstufe von Tropasäure und Benzoesäure. Arch. Pharm. 296, 1 (1963).

22. Hamon, N. W. and J. L. Eyolfson: Biosynthesis of tropic acid in Datura innoxia root rissue. J. Pharm. Sci. 61, 2006 (1972).

23. Kaczkowski, J. and L. Marion: The incorporation of putrescine into hyoscyamine. Can. J. Chem. 41, 2651 (1963).

24. Kaczkowski, J., H. R. Schütte and K. Mothes: Die Rolle des Acetats in der Biosynthese der Tropanalkaloide. Biochim. Biophys. Acta 46, 588 (1961).

25. Kalantyr, M. S. and Y. B. Tikhonov: Suc- 
cinic acid as a precursor of tropane alkaloids. Khim. Prir. Soedin 3, 395 (1967).

26. Leete, E.: The stereospecific incorporation of ornithine into the tropine moiety of hyoscyamine. J. Am. Chem. Soc. 84, 55 (1962).

27. Leete, E.: Biosynthesis of hyoscyamine. Proof that ornithine $-2-{ }^{14} \mathrm{C}$ yields tropine labelled at C-1. Tetrahedron Lett. 1619 (1964).

28. Leete, E.: Biosynthesis of meteloidine. Phytochemistry 11, 1713 (1972).

29. Leete, E.: Biosynthesis of tropic acid, in T. A. Geissman (ed.): Biosynthesis, Specialist Periodical Report, Chemical Society, Vol. 2, pp. 115 (1973).

30. Leete, E.: Biosynthetic conversion of $\alpha$-methylbutyric acid to tiglic acid in Datura meteloides. Phytochemistry 12, 2203 (1973).

31. Leete, E. and E. Bellion: Unpublished work (1970).

32. Leete, E. and E. G. Gros: In discussion of paper by J. C. Woolley. The biosynthesis of the tigloyl esters in Datura. Abh. Dtsch. Akad. Wiss. Berlin, Kl. Chem., Geol., Biol., 3, 538 (1966).

33. Leete, E. and E. P. Kirven: Biosynthesis of tropic acid: Feeding experiments with cinnamoyltropine and littorine. Phytochemistry 13, 1501 (1974).

34. Leete, E., N. Kowanko and R. A. Newmark: Use of carbon-13 nuclear magnetic resonance to establish that the biosynthesis of tropic acid involves an intramolecular rearrangement of phenylalanine. J. Am. Chem. Soc. 97, 6826 (1975).

35. Leete, E., N. Kowanko, R. A. Newmark, L. C. Vining, A. G. McInnes and J. L. C. Wright: The use of carbon-13 nuclear magnetic resonance to establish that the biosynthesis of tenellin involves an intramolecular rearrangement of phenylalanine. Tetrahedron Lett. 4103 (1975).

36. Leete, E. and M. C. L. Louden: Incorporaand H. R. Schütte: Zur Biosynthese der tion of putrescine into the tropine moiety of hyoscyamine. Chem. and Ind. (London) 1725 (1963).

37. Leete, E. and D. H. Lucast: Biosynthesis of meteloidine from $3 \alpha$-tigloyloxytropane in Datura innoxia. Phytochemistry 14, 2199 (1975).
38. Leete, E. and D. H. Lucast: Loss of tritium during the biosynthesis of meteloidine and scopolamine from $\left[\mathrm{N}-\right.$ methyl $-{ }^{14} \mathrm{C}, 6 \beta, 7 \beta$ $\left.{ }^{3} \mathrm{H}_{2}\right]$ tropine. Tetrahedron Lett. 3401 (1976).

39. Leete, E., L: Marion and I. D. Spenser: The biogenesis of alkaloids. XII. The mode of formation of the tropine base of hyoscyamine. Can. J. Chem. 32, 1116 (1954).

40. Leete, E. and J. B. Murrill: Biosynthesis of the tiglic acid moiety of meteloidine in Datura meteloides. Tetrahedron Lett. 1727 (1967).

41. Leete, E. and S. J. Nelson: Biosynthesis of teloidine moiety of meteloidine in Datura meteloides. Phytochemistry 8, 413 (1969).

42. Leete, E. and M. L. Yu: Unpublished work (1978) on the biosynthesis of cocaine involving feedings of $\left[2-{ }^{14} \mathrm{C}\right]$-ornithine and [2$\left.{ }^{14} \mathrm{C}\right]-\mathrm{N}$-methyl- $\Delta^{\mathbf{1}}$-pyrrolinium salt to Erythroxylon coca.

43. Liebisch, H. W.: Formation of tropic acid in vivo and in vitro. 7th IUPAC meeting on Natural Products, Riga. Abstracts p. 557 (1970).

44. Liebisch, H. W., H. Bernasch and H. R. Schütte: Zur Biosynthese der Tropanalkaloide XII; Die Biosynthese des Cochlearins. Z. Chem. 13, 372 (1973).

45. Liebisch, H. W., W. Maier and H. R. Schütte: Zur Biosynthese der Tropanalkaloide VI. N-Methylputrescine als eine mögliche Vorstufe des Pyrrolidinringes in Hyos- cyamin und Scopolamin. Tetrahedron Lett. 4079 (1966).

46. Liebisch, H. W., K. Peisker, A. S. Radwan and H. R. Schütte: Zur Biosynthese der Tropanalkaloide. XI. Die Bildung der $\mathrm{C}_{3}$ Brïcke des Tropins. Z. Pflanzenphysiol 67, 1 (1972).

47. Liebisch, H. W., A. S. Radwan and H. R. Schütte: Zur Biosynthese der Tropanalkaloide, X. Uber die Bildung des Cuskhygrins. Annalen 721, 163 (1969).

48. Liebisch, H. W., H. Ramin, I. Schöffinius Tropanalkaloide. IV. Z. Naturforsch. 20b, 1183 (1965).

49. Liebisch, H. W. and H. R. Schütte: Zur Biosynthese der Tropanalkaloide. VIII. Vorstufen des Pyrrolidinringes. Z. Pflanzenphysiol. 57, 434 (1967).

50. Liebisch, H. W., H. R. Schütte and K. Mothes: Zur Biosynthese der Tropanalkaloide, 
IV. Putrescin als mögliche Vorstufe des Pyrrolidin-Rings der Tropan-alkaloide. Annalen 668,139 (1963).

51. Loder, J. W. and G. B. Russell: Tropine 1,2-dithiolane-3-carboxylate, a new alkaloid from Bruguiera senangula. Tetrahedron Lett. 6327 (1966).

52. Lounasmaa, M.: On the minor alkaloids of Knightia deplanchei. Planta Medica 27, 83 (1975).

53. Lounasmaa, M., P. M. Wookulich and E. Wenkert: Structures of some Knightia deplanchei alkaloids. J. Org. Chem. 40, 3694 (1975).

54. McGaw, B. A. and J. G. Woolley: Stereochemistry of tropane alkaloid formation in Datura Phytochemistry 17, 257 (1978).

55. Mestichelli, L. J. J., R. N. Gupta and I. D. Spenser: The biosynthetic route from ornithine to proline. J. Biol. Chem. 254, 640 (1979).

56. Mizusaki, S., T. Kisaki and E. Tamaki: Phytochemical studies on the tobacco alkaloids. XII. Identification of $\gamma$-methylaminobutyraldehyde and its precursor role in nicotine biosynthesis. Plant Physiol. 43, 93 (1967).

57. Motherwell, W. D. S., N. W. Isaacs, O. Kennard, I. R. C. Bick, J. B. Bremner and J. Gillard: Bellendine, the first proteaceous alkaloid, a $\gamma$-pyronotropane: X-ray structure determination by direct methods. Chem. Commun. 133 (1971).

58. Neumann, D. and H. B. Schröter: N-Methylornithin als Vorstufe des Pyrrolidin rings in Tropanalkaloiden. Tetrahedron Lett. 1273 (1966).

59. O'Donovan, D. G. and M. F. Keogh: The role of hygrine in the biosynthesis of cuscohygrine and hyoscyamine. J. Chem. Soc. (C) 223 (1969).

60. Prabhu, B. V.: The biosynthesis of tropic acid. Ph. D. Thesis, University of Georgia (1974).

61. Prabhu, B. V., C. A. Gibson and L. C. Schramm: Biosynthesis of tropic acid. I. Incorporation of cinnamic acid-2-14C in Datura innoxia. Lloydia 39, 79 (1976).

62. Robinson, W. G., B. K. Bachhawat and M. J. Coon: Tiglyl coenzyme A and $\alpha$-methylacetoacetyl coenzyme $\mathrm{A}$, intermediates in the enzymic degradation of isoleucine. J. Biol. Chem. 218, 391 (1956).
63. Romeike, A.: Ưber die Mitwirkung des Sprosses bei der Ausbildung des Alkaloidspektrums. I. Epoxydbildung beim Hyoscyamin durch Datura ferox. L. Flora 143 , 67 (1956).

64. Romeike, A.: Uber die Mitwirkung des Sprosses bei der Ausbildung des Alkaloidspektrums. II. Bildungsstätte und Biogenese des Scopolamins in Datura ferox. L. Flora 148, 306 (1959).

65. Romeike, A.: Uber das Vorkommen von 6Hydroxyhyoscyamin in Datura. Naturwissenschaften 49, 281 (1962).

66. Romeike, A. and G. Fodor: The biogenesis of hyoscine in Datura stramonium L. Tetrahedron Lett. No. 22, 1 (1960).

67. Schütte, H. R. and H. W. Liebisch: Zur Biosynthese der Tropanalkaloide. Zum Mechanismus der Bildung der Tropasäure aus Phenylalanin- $\left(1-{ }^{14} \mathrm{C}, 2-{ }^{3} \mathrm{H}\right)$. Z. Pflanzenphysiol. 57, 440 (1967).

68. Spenser, I. D.: The biosynthesis of alkaloids and of other nitrogenous secondary metabolites, in M. Florkin and E. H. Stotz (eds): Comprehensive Biochemistry, Vol. 20, Chap. VI, pp. 231, ref. (116), 1968.

69. Tamprateep, P., E. H. Tayler and E. Ramstad: Biosynthesis of the alkaloids of Erythroxylon novogronatense. Lloydia 26, 203 (1963).

70. Underhill, E. W. and H. W. Youngken: Biosynthesis of hyoscyamine and scopolamine in Datura stramonium. J. Pharm. Sci. 51, 121 (1962).

71. Woolley, J. G.: The biosynthesis of tigloyl esters in Datura. Abh. Dtsch. Akad. Wiss. Berlin Kl. Chem., Geol., Biol., Nr. 3, pp. 531 (1966).

72. Yamasaki, K., T. Tamaki, S. Uzawa, U. Sankawa and S. Shibata: Participation of $\mathrm{C}_{6}-\mathrm{C}_{1}$ unit in the biosynthesis of ephedrine in Ephedra. Phytochemistry 12, 2877 (1973).

73. Zenk, H. M.: Metabolism of prearomatic and aromatic compounds in plants, in $\mathrm{H}$. Wagner and L. Hörhammer (eds): Pharmacognosy and Phytochemistry, pp. 330-339, Berlin 1971, Springer Verlag.

Address: Professor Edward Leete, School of Chemistry, University of Minnesota, Minneapolis, 55455, USA 